\title{
ESR Study of the Propagating Radicals of Diene Compounds in Frozen State. Conformations, Spin Densities, and Reactivities of the Propagating Radicals
}

\author{
Mikiharu KamachI, Hiroyuki Umetani, Yoko KuwaE, \\ and Shun-ichi NOZAKURA
}

Department of Macromolecular Science, Faculty of Science, Osaka University, Toyonaka, Osaka 560, Japan

(Received June 27, 1983)

\begin{abstract}
An ESR study on the radical polymerization of diene compounds was carried out in frozen aromatic solvents, using benzoyl peroxide as a photoinitiator. The diene compounds were $\mathrm{CH}_{2}=\mathrm{CHX}-\mathrm{CH}=\mathrm{CHY}\left(\mathrm{X}=\mathrm{OCH}_{3}\right.$ and $\mathrm{Y}=\mathrm{COOCH}_{2} \mathrm{CH}_{3}, \mathrm{X}=\mathrm{CH}_{3}$ and $\mathrm{Y}=\mathrm{COOCH}_{2} \mathrm{CH}_{3}$, $\mathrm{X}=\mathrm{H}$ and $\mathrm{Y}=\mathrm{COOCH}_{2} \mathrm{CH}_{3}$, and $\mathrm{X}=\mathrm{H}$ and $\mathrm{Y}=\mathrm{OCOCH}_{3}$ ). Spectra were observed at $-120^{\circ} \mathrm{C}$. The hyperfine splitting constants show that the propagating radical ends are allylic radicals whose unpaired electrons were completely delocalized over the three carbons of their chain ends. The conformation and spin density of the radical ends were estimated from the hyperfine splitting constants of methylene protons adjacent to the radicals and $\alpha$-protons. The conformations could be explained by a single conformation. The reactivity of the propagating radicals was estimated from the propagation rate constants for radical polymerizations and reactivity ratios in the copolymerizations with styrene. The relation between the spin density and reactivity of the propagating radicals is discussed.
\end{abstract}

KEY WORDS ESR / Ethyl 4-Ethoxy-2,4-pentadienoate / Ethyl 4-Methyl-

2,4-pentadienoate / Ethyl 2,4-Pentadienoate / 1-Acetoxybutadiene /

Conformation / Spin Density / Hyperfine Splitting / Reactivity Ratio /

Microstructure /

ESR spectroscopy is considered the most useful method for understanding the properties and structures of propagating radicals. ${ }^{1,2}$ However, only a few papers have been published on ESR study carried out above room temperature, ${ }^{3-5}$ since the concentration of propagating radicals is too low to be detected by a conventional ESR spectrometer. Accordingly, the solid state polymerization ${ }^{6}$ and flow method $^{7}$ were used for the study of propagating radicals. A number of papers have been published on solid state polymerization, ${ }^{1}$ but the ESR spectra of polymer radicals have not been wellresolved except in a number of cases. ${ }^{7-12}$ Recently, we found some aromatic compounds to be good media for observing well-resolved ESR spectra in the photosensitized polymerization of MMA and its homologs in the frozen state. ${ }^{13,14}$ This method was applied to the polymerization of diene monomers to obtain information on the nature of the propagat- ing radicals.

In this paper, we report on the conformation and spin density of the propagating radicals of diene compounds in the frozen state and discuss the relation between the spin density and reactivity of the propagating radicals.

\section{EXPERIMENTAL}

Ethyl 4-ethoxy-2,4-pentadienoate (EEP, trans: $c i s=92: 8$ ) was prepared as shown in a previous paper. ${ }^{15}$ Bp $60^{\circ} \mathrm{C} / 0.5 \mathrm{~mm}$. Ethyl trans-4-methyl2,4-pentadienoate (EMP) and ethyl 2,4-pentadienonate (EP) were similarly prepared from methacrolein and acrolein, respectively. Bp (EMP) $50.0^{\circ} \mathrm{C} /$ $3.5 \mathrm{~mm}$ and (EP) $36.5^{\circ} \mathrm{C} / 5 \mathrm{~mm}$. 1-Acetoxybutadiene $(\mathrm{AB})$ was synthesized according to Wichterle's method. ${ }^{16} \mathrm{Bp} 34^{\circ} \mathrm{C} / 12 \mathrm{~mm}$. Commercially available vinyl acetate, styrene, benzonitrile, 
benzoyl peroxide (BPO), and $\alpha, \alpha^{\prime}$-azobis(isobutyronitrile) (AIBN) were purified as described previously. ${ }^{17,18}$

$$
\begin{gathered}
\stackrel{\mathrm{OC}_{2} \mathrm{H}_{5}}{\mathrm{I}} \underset{\mathrm{CH}}{\mathrm{C}}-\mathrm{CH}=\underset{1}{\mathrm{CH}} \\
\stackrel{\mathrm{COOC}}{2} \mathrm{H}_{5}
\end{gathered}
$$

EEP<smiles>C=C(C)C=CC(=O)OCC</smiles>

EMP

$\begin{aligned} \mathrm{CH}_{2}=\mathrm{CH}-\mathrm{CH}= & \underset{\text { }}{\mathrm{CH}} \\ & \mathrm{COOC}_{2} \mathrm{H}_{5}\end{aligned}$

EP

$$
\begin{aligned}
\mathrm{CH}_{2}=\mathrm{CH}-\mathrm{CH}= & \underset{1}{\mathrm{C}} \mathrm{H} \\
& \mathrm{OCOCH}_{3}
\end{aligned}
$$

$\mathrm{AB}$

Polymerization and copolymerization were carried out in benzene at $60^{\circ} \mathrm{C}$ using AIBN as the initiator. Polymers and copolymers were isolated and purified by repeated reprecipitation from benzene-hexane. Rate constant measurement for the radical polymerizations of diene compounds will be reported elsewhere. ${ }^{19}$

The microtacticities of the polymers were estimated from the relative intensities of the resonance signals of the NMR spectra recorded by a Varian A60 spectrometer. The relative intensity of the signals was determined by an integrator.

ESR spectra were measured in solutions of diene compounds $(2.0 \mathrm{M})$ and $\mathrm{BPO}(0.01 \mathrm{M})$ in benzonitrile at $-120^{\circ} \mathrm{C}$ to $-80^{\circ} \mathrm{C}$ under UV irradiation by a JEOL JES-FE 1X ESR spectrometer. The light source was a $500 \mathrm{~W}$ high pressure mercury lamp (USHIO 500). ESR spectra were simulated by a JEOL EC-6 computer (Program No. 398).

\section{RESULTS}

\section{ESR Spectra of Propagating Radicals}

The ESR spectrum of the photosensitized po- lymerization system of EMP in the rigid glass of benzonitrile at $-120^{\circ} \mathrm{C}$ is shown in Figure 1a. The intensity of the spectrum decreased with an increase in the polymerization temperature, but the intensity distribution did not change until the spectrum disappeared at about $-80^{\circ} \mathrm{C}$. The spectrum consisted of 6 lines with a hyperfine splitting of about $10.50 \mathrm{G}$. No ESR spectrum was observed in the absence of BPO. The spectrum was simulated with $\mathrm{A}_{\mathrm{H}^{1}}=10.90 \mathrm{G}, \mathrm{A}_{\mathrm{H}^{2}}=4.50 \mathrm{G}, \mathrm{A}_{\mathrm{CH}_{3}}=10.70 \mathrm{G}$, $\mathrm{A}_{\mathrm{H}^{4}}=10.60 \mathrm{G}$, and $\mathrm{A}_{\mathrm{H}^{5}}=2.80 \mathrm{G}$, on the assumption

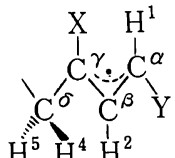

$$
\begin{aligned}
& \mathrm{X}=\mathrm{CH}_{3} \quad \text { and } \mathrm{Y}=\mathrm{COOC}_{2} \mathrm{H}_{5} \text { for EMP } \\
& =\mathrm{OC}_{2} \mathrm{H}_{5} \text { and }=\mathrm{COOC}_{2} \mathrm{H}_{5} \text { for EEP } \\
& =\mathrm{H}^{3} \text { and }=\mathrm{COOC}_{2} \mathrm{H}_{5} \text { for } \mathrm{EP} \\
& =\mathrm{H}^{3} \text { and }=\mathrm{OCOCH}_{3} \text { for } \mathrm{AB}
\end{aligned}
$$

of a Gaussian with linewidth of $8.4 \mathrm{G}$. The apparent 6 line spectrum was considered due to the fact that hyperfine splittings with $\mathrm{A}_{\mathrm{H}^{2}}$ and $\mathrm{A}_{\mathrm{H}^{5}}$ were smeared out because of the broad linewidth. Since $A_{H^{1}}$ and $\mathrm{A}_{\mathrm{CH}_{3}}$ were almost half of the hyperfine splitting due to the $\alpha$-protons $(20.4 \mathrm{G})$ of the polyacrylate radi$\mathrm{cal}^{1}$ and the methyl protons $(22.4 \mathrm{G})$ of the poly(MMA) radical, ${ }^{1}$ respectively, the unpaired electron of the poly(EMP) radical is ascribed to an allylic radical.

The 4-line spectra were observed for $\mathrm{EP}$ and $\mathrm{AB}$ as show in Figures $1 \mathrm{~b}$ and 1c. Simulation gave the coupling constants shown in Table I. In both cases, the value of $A_{H^{1}}$ was the same as that of $A_{H^{3}}$, indicating that the unpaired electron of the propagating radical was completely delocalized over the allylic three carbons.

The 3-line spectrum was observed for EEP and simulated as shown in Figure 1d and Table I. Since the hyperfine splittings due to $\mathrm{A}_{\mathrm{H}^{2}}$ and $\mathrm{A}_{\mathrm{H}^{5}}$ were smaller than the linewidth, fine structures resulting from the hyperfine splittings could not be observed, but $\mathrm{A}_{\mathrm{H}^{2}}$ and $\mathrm{A}_{\mathrm{H}^{5}}$ were important for obtaining the best fit between the computer-simulated and observed spectra. Since the values of $A_{\mathrm{H}^{1}}$ and $\mathrm{A}_{\mathrm{H}^{2}}$ of the radicals are similar to those of EP or EMP, the propagating radical was concluded to be allylic.

To compare the hyperfine splitting constants of $A B$ with those of vinyl acetate, the ESR spectrum of 
ESR Study on the Radical Polymerization of Dienes

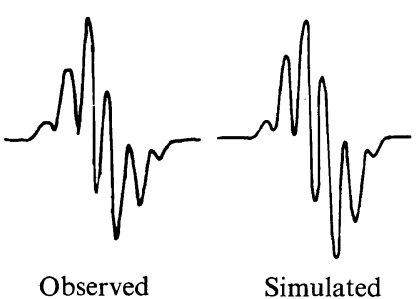

a

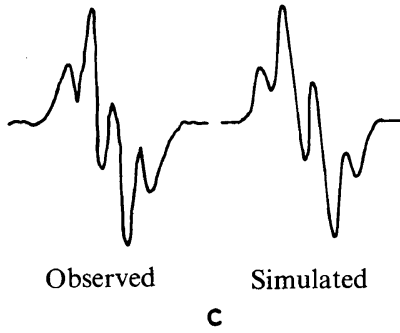

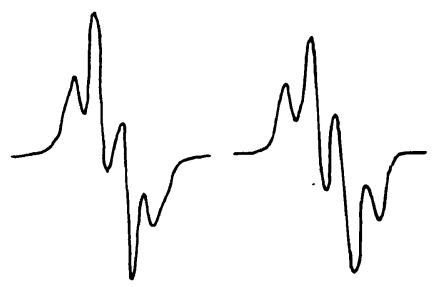

Observed b

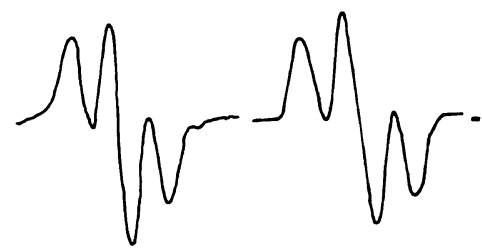

Observed

d

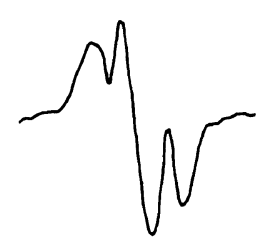

Observed

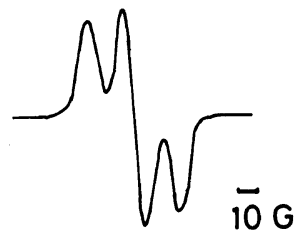

Simulated

Figure 1. Observed and simulated ESR spectra of propagating radicals in frozen benzonitrile at $-120^{\circ} \mathrm{C}$. (a) EMP; (b) EP; (c) AB; (d) EEP; (e) VAc.

Table I. Hyperfine splitting constants and linewidths (Gauss)

\begin{tabular}{lccrccc}
\hline Monomer & $\mathrm{A}_{\mathrm{H}^{1}}$ & $\mathrm{~A}_{\mathrm{H}^{2}}$ & $\mathrm{~A}_{\mathbf{X}}$ & $\mathrm{A}_{\mathrm{H}^{4}}$ & $\mathrm{~A}_{\mathrm{H}^{5}}$ & Linewidth \\
\hline $\mathrm{EEP}^{\mathrm{a}}$ & 11.00 & 4.50 & - & 10.50 & 3.00 & 8.4 \\
$\mathrm{EMP}^{\mathrm{a}}$ & 10.90 & 4.50 & 10.70 & 10.60 & 2.80 & 8.4 \\
$\mathrm{EP}^{\mathrm{a}}$ & 10.80 & 4.50 & 10.85 & 16.00 & 0.20 & 8.4 \\
$\mathrm{AB}^{\mathrm{a}}$ & 13.80 & 5.50 & 13.30 & 16.00 & 0.20 & 9.0 \\
$\mathrm{VAc}^{\mathrm{b}}$ & 22.00 & 21.00 & 9.00 & - & - & 14.0 \\
\hline
\end{tabular}

a $\mathrm{X},-\mathrm{OC}_{2} \mathrm{H}_{5}$ (EEP), $-\mathrm{CH}_{3}$ (EMP), and $-\mathrm{H}^{3}$ (EP, $\left.\mathrm{AB}\right)$.

b $\mathrm{A}_{\mathrm{H}^{1}}, \alpha$-proton hyperfine splitting constants and $\mathrm{A}_{\mathrm{H}^{2}}$ and $\mathrm{A}_{\mathrm{H}^{3}}, \beta$-methylene proton hyperfine splitting constants.

the propagating radical of vinyl acetate was measured in the frozen state and simulated as shown in Figure le and Table I. The hyperfine splitting due to $\mathrm{A}_{\mathrm{H}^{3}}$ was smeared out in the 3-line spectrum because of the broad linewidth. The value of $A_{\mathbf{H}^{1}}$ of vinyl acetate was about twice that of $\mathrm{AB}$, indicating that the unpaired electron from $\mathrm{AB}$ was completely delocalized over the three carbons of the chain end.

\section{NMR Spectra of Polymers}

A structure analysis of polymers was carried out by NMR. The ${ }^{1} \mathrm{H}$ NMR spectra of the polymers are shown in Figures 2-5. The Polymers were considered to consist of the 1,4-, 1,2- and 3,4-addition units shown below.

$$
\begin{aligned}
& -\mathrm{CH}_{2}-\mathrm{CX}=\mathrm{CH}-\mathrm{CHY}- \\
& \text { 1,4-unit }
\end{aligned}
$$

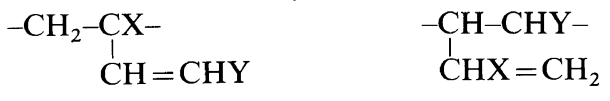

$$
\begin{aligned}
& \text { 3,4-unit 1,2-unit } \\
& \mathrm{X}=\mathrm{H}, \mathrm{CH}_{3} \text { or } \mathrm{OC}_{2} \mathrm{H}_{5} \\
& \mathrm{Y}=\mathrm{COOC}_{2} \mathrm{H}_{5} \text { or } \mathrm{OCOCH}_{3}
\end{aligned}
$$




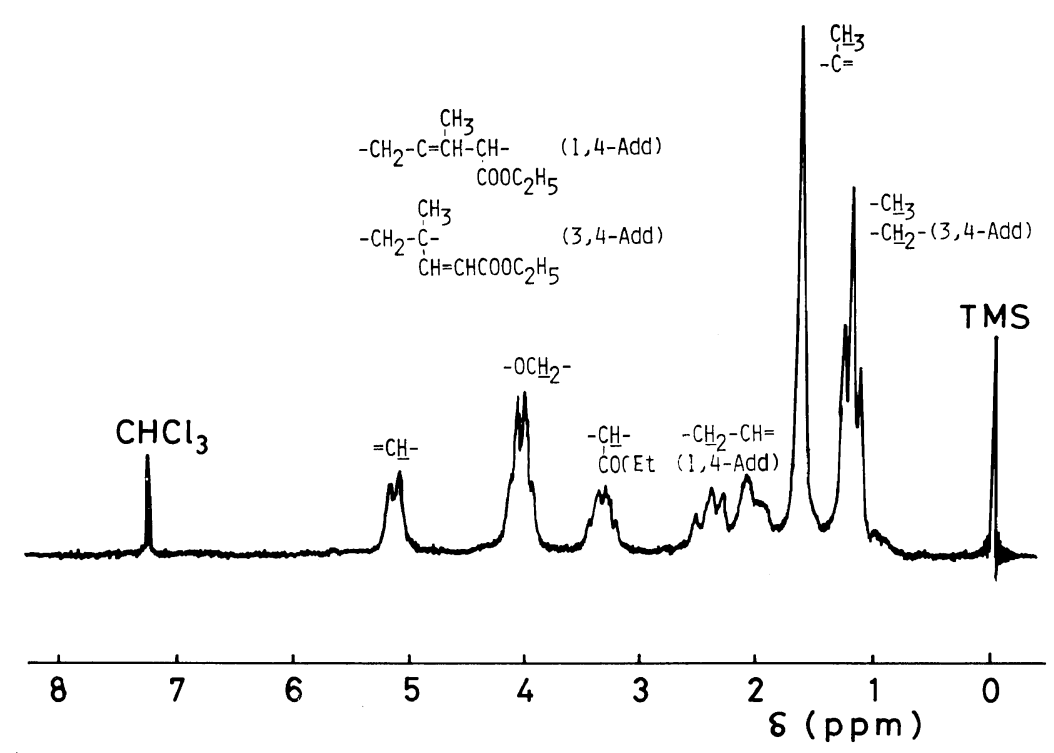

Figure 2. NMR spectrum of poly(EMP) in $\mathrm{CDCl}_{3}$ at $50^{\circ} \mathrm{C}$.

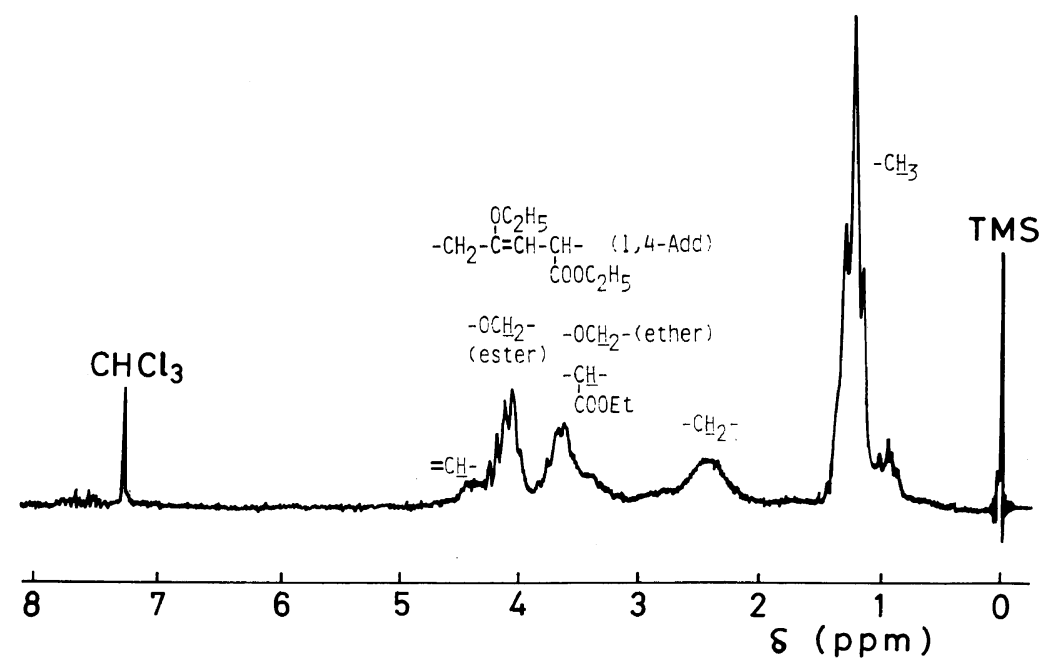

Figure 3. $\mathrm{NMR}$ spectrum of poly(EEP) in $\mathrm{CDCl}_{3}$ at $50^{\circ} \mathrm{C}$.

In poly(EMP) (Figure 2), no signals attributable to vinylidene protons $\left(\mathrm{CH}_{2}=\right)$ resulting from the 1,2-addition could be detected in the olefinic proton region $(4.5-5.2 \mathrm{ppm})^{19}$; a weak signal due to methylene proton from the 3,4-addition was observed at $1.32 \mathrm{ppm}$ as a shoulder of methyl peaks at $1.15 \mathrm{ppm}$. The ratio of the 1,4- to 3,4-addition unit in poly(EMP) (A:B) was calculated to be $90: 10$ from the intensity ratio of the signals of two kinds of methyl groups $\left[\mathrm{CH}_{3} \mathrm{CH}_{2}-,-\left(\mathrm{CH}_{3}\right) \mathrm{C}-\mathrm{CH}_{2}-\right]$ and one kind of methylene group $\left[-\mathrm{CH}_{2}-\mathrm{C}\left(\mathrm{CH}_{3}\right)=\right]$ at about $1.15 \mathrm{ppm}\left(I_{1.15}\right)$ to that of methyl protons $\left[-\left(\underline{\mathrm{CH}}_{3}\right) \mathrm{C}=\right]$ at $1.66 \mathrm{ppm}\left(I_{1.66}\right)$, using the following scheme:

$$
\frac{I_{1.15}}{I_{1.66}}=\frac{4.25}{3.25}=\frac{3 \mathrm{~A}+8 \mathrm{~B}}{3 \mathrm{~A}}
$$

The relative ratios of the other peaks could be resonably explained by this ratio of the 1,4- to 3,4unit.

In poly(EEP) (Figure 3), no signal other than the vinyl ether moiety $(-(\mathrm{OEt}) \mathrm{C}=\underline{\mathrm{CH}}-, 4.2-4.3 \mathrm{ppm})$ 
ESR Study on the Radical Polymerization of Dienes

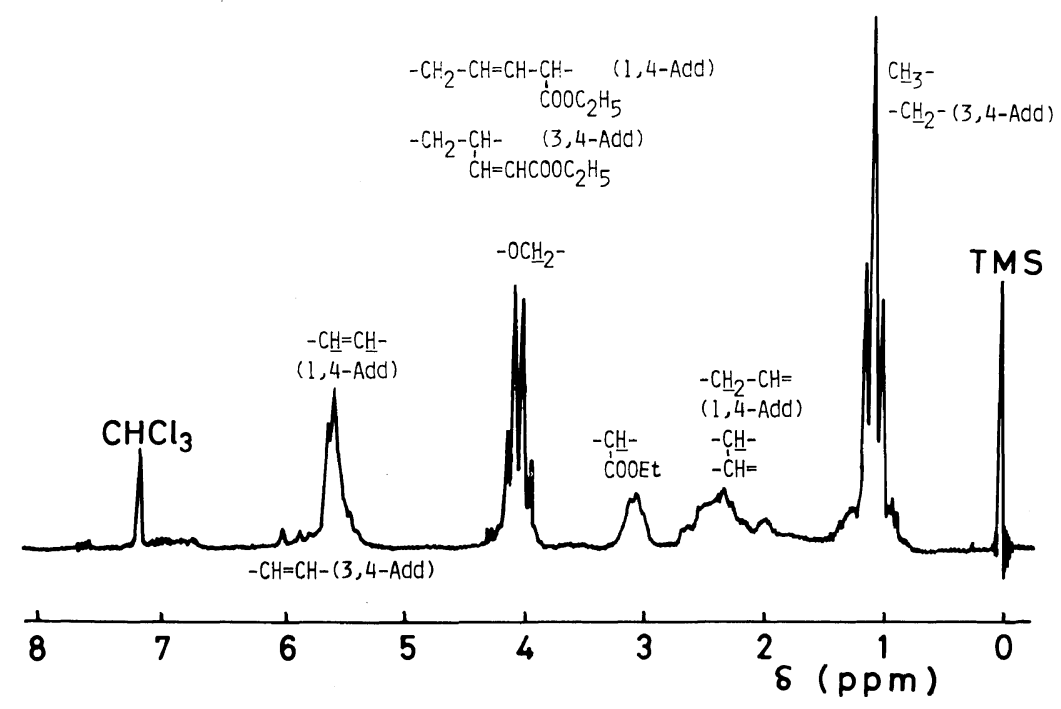

Figure 4. NMR spectrum of poly(EP) in $\mathrm{CDCl}_{3}$ at $50^{\circ} \mathrm{C}$.

$$
\begin{gathered}
-\mathrm{CH}_{2}-\mathrm{CH}=\mathrm{CH}-\mathrm{CH}-\quad(1,4-\mathrm{Add}) \\
\mathrm{OCOCH} \\
-\mathrm{CH}_{2}-\mathrm{CH}-\stackrel{\mathrm{CH}}{\mathrm{CH}=\mathrm{CHOCOCH}}(1,2-\mathrm{Add})
\end{gathered}
$$
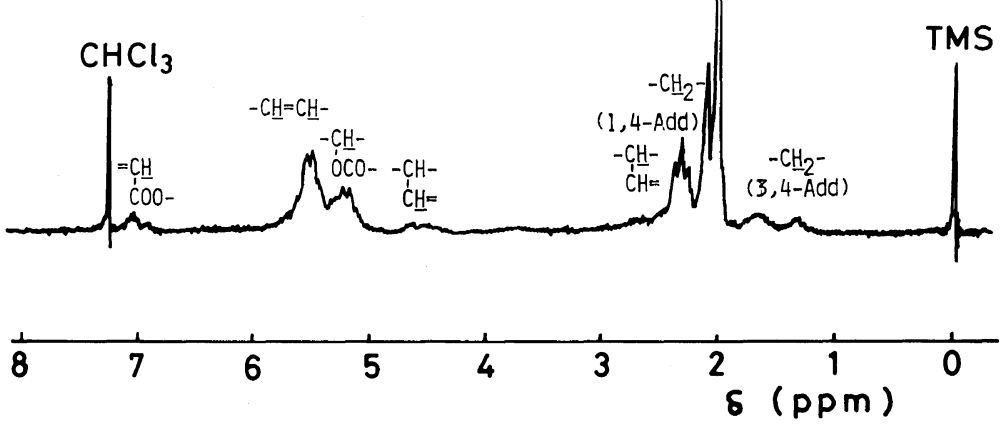

Figure 5. $\mathrm{NMR}$ spectrum of $\operatorname{poly}(\mathrm{AB})$ in $\mathrm{CDCl}_{3}$ at $50^{\circ} \mathrm{C}$.

of the 1,4-addition unit could be observed in the olefinic proton region from $4.5 \mathrm{ppm}$ to $7.0 \mathrm{ppm} .^{20}$ Therefore, the content of the 1,2- and 3,4-addition unit was considered to be negligible. A small triplet resonance signal at $0.95 \mathrm{ppm}$ was probably due to the methyl protons obtained from the 1,4-addition of the cis isomer which could not be separated from the trans isomer since the ratio of the intensity of the resonance at $1.25 \mathrm{ppm}$ to that of $0.95 \mathrm{ppm}(94: 6)$ was almost consistent with the initial ratio of the geometrical isomers $(92: 8)$. Each peak of poly(EEP) was resonably assigned by the 1,4-addition unit as previously reported. ${ }^{15}$

In poly(EP) (Figure 4), no signal could be detected in the region from $4.5 \mathrm{ppm}$ to $5.2 \mathrm{ppm}$ where vinilidene protons of the vinyl group binding to a carbon atom gave a resonance peak. ${ }^{20}$ Therefore, the possibility of a 1,2-addition is ruled out. Weak resonance peaks from 5.8 to $6.1 \mathrm{ppm}$ could be attributed to some parts of $-\mathrm{CH}=\mathrm{CHCOOC}_{2} \mathrm{H}_{5}$, 
indicating that the 3,4-addition unit should be taken into account. The presence of the 3,4-unit was also supported by the signal of methylene protons at $1.28 \mathrm{ppm}$. The ratio of the $1.4-$ to $3,4-$ unit in poly(EP) (A:B) was calculated to be $80: 20$ from the intensity ratio of the signal of the two kinds of methyl protons and one kind of methylene proton at $1.06 \mathrm{ppm}\left(I_{1.06}\right)$ to that of the methine proton at $3.08 \mathrm{ppm}\left(I_{3.08}\right)$, using the following scheme:

$$
\frac{I_{1.06}}{I_{3.08}}=\frac{7.71}{1.82}=\frac{3 \mathrm{~A}+5 \mathrm{~B}}{\mathrm{~A}}
$$

All peaks and their relative intensities could be explained by the 1,4- and 3,4-units.

In poly $(\mathrm{AB})$ (Figure 5), the olefinic proton signals at 4.6 and $7.0 \mathrm{ppm}$ indicate the presence of the $\beta$ substituted vinyl acetate moiety. Therefore, a considerable number of 3,4-addition units were present in poly (AB). Since the 1,2-addition unit results from the polymerization of the inner olefinic part of $\mathrm{AB}$, the content of the 1,2-unit seems quite low compared with that of the 1,4- and 3,4-units. However, since there are no data to exclude the presence of the 1,2-units, the content of the 1,4-, 3,4-, and 1,2-units in the ratio, $A: B: C$, was calculated from the intensity ratio for the resonances in the three regions $(1.0-4.0,4.0-6.0$, and $7.0 \mathrm{ppm}$, having the intensities, $I_{\mathrm{a}}, I_{\mathrm{b}}$, and $I_{\mathrm{c}}$, respectively) by the following schemes:

$$
\frac{I_{\mathrm{a}}}{I_{\mathrm{c}}}=\frac{5.82}{0.41}=\frac{5 \mathrm{~A}+6 \mathrm{~B}+4 \mathrm{C}}{\mathrm{B}}
$$

and

$$
\frac{I_{\mathrm{b}}}{I_{\mathrm{c}}}=\frac{2.42}{0.41}=\frac{3 \mathrm{~A}+\mathrm{B}+4 \mathrm{C}}{\mathrm{B}}
$$

The results indicated a 1,2-unit content of zero, and that all peaks could be explained by the 1,4- and 3,4units in the ratio, $62: 38$.

From the microstructure of poly(diene)s, the order of increasing magnitude of 1,4-unit content was concluded to be poly(EEP) $>$ poly $($ EMP $)>$ $\operatorname{poly}(\mathrm{EP})>\operatorname{poly}(\mathrm{AB})$.

\section{Rate Constants and Reactivity Ratios}

To gain some understanding of the reactivity of diene compounds and their propagating radicals, the homopolymerization and copolymerization with styrene were performed in benzene at $60^{\circ} \mathrm{C}$, using AIBN as the initiator. A few reactivity ratios

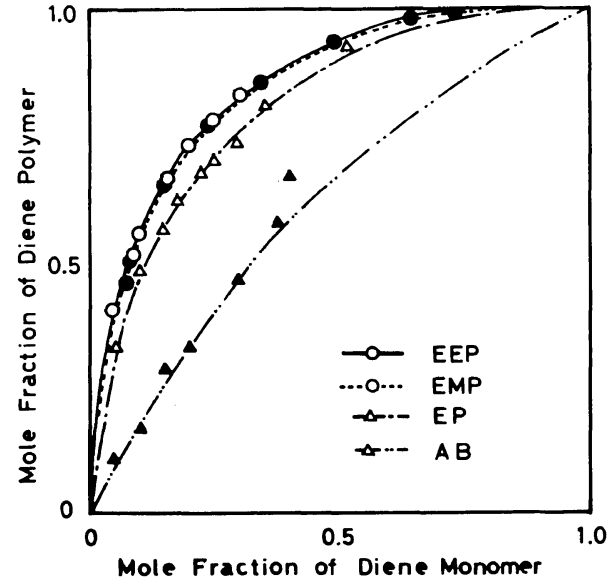

Figure 6. Copolymer composition curves of styrene and dienes.

\begin{tabular}{|c|c|c|c|c|}
\hline Monomer & $r_{1}$ & $r_{2}$ & $Q$ & $e$ \\
\hline $\mathrm{EEP}^{\mathrm{b}}$ & $\begin{array}{c}0.08 \pm 0.01 \\
(0.07)\end{array}$ & $\begin{array}{c}10.48 \pm 0.00 \\
(10.10)\end{array}$ & 8.94 & -0.38 \\
\hline $\mathrm{EMP}^{\mathrm{b}}$ & $\begin{array}{c}0.06 \pm 0.00 \\
(0.08)\end{array}$ & $\begin{array}{c}10.59 \pm 0.00 \\
(11.26)\end{array}$ & 9.57 & -0.16 \\
\hline $\mathrm{EP}^{\mathrm{b}}$ & $\begin{array}{c}0.09 \pm 0.01 \\
(0.09)\end{array}$ & $\begin{array}{c}5.75-0.00 \\
(5.65)\end{array}$ & 5.86 & 0.02 \\
\hline $\mathrm{AB}^{\mathrm{b}}$ & $\begin{array}{c}0.45 \pm 0.06 \\
(0.43)\end{array}$ & $\begin{array}{c}1.78 \pm 0.03 \\
\quad(1.47)\end{array}$ & 3.19 & -1.26 \\
\hline Butadiene ( $\mathrm{Bu}$ & $25 \quad 0.78$ & 1.39 & 2.39 & -1.05 \\
\hline
\end{tabular}

Table II. Monomer reactivity ratios ${ }^{\mathrm{a}}$ and $Q-e$ values at $60^{\circ} \mathrm{C}$

${ }^{\text {a }} \mathrm{M}_{1}$, styrene; $\mathrm{M}_{2}$, diene.

b The values in parentheses were obtained by the KelenTüdõs methods.

in the copolymerizations of similar diene compounds have been reported by different groups so far. ${ }^{21,22}$ Since there is, however, some variation in data, we attempted to determine reactivity ratios for an accurate comparison of reactivity. The copolymer composition curves are shown in Figure 6 Conversions were kept below $5 \%$ in all copolymerizations. Reactivity ratios were calculated using both the Fineman-Ross ${ }^{23}$ and Kelen-Tüdõs ${ }^{24}$ methods and are shown in Table II along with the reported data for butadiene. ${ }^{25}$ Since similar reactivity ratios were obtained by both calculation methods in all copolymerization systems, a discussion on the monomer reactivity ratio should be made-the reactivity of diene compounds with polystyryl radicals 
Table III. Rate constants for radical polymerizations of diene compounds at $25^{\circ} \mathrm{C}$

\begin{tabular}{|c|c|c|}
\hline \multirow{2}{*}{ Monomers } & $k_{\mathrm{p}}$ & $k_{\mathrm{t}}$ \\
\hline & $M^{-1} s^{-1}$ & $\mathbf{M}^{-1} \mathrm{~s}^{-1}$ \\
\hline EEP & 10 & $0.9 \times 10^{7}$ \\
\hline EMP & 30 & $2.3 \times 10^{7}$ \\
\hline EP & 31 & $1.9 \times 10^{7}$ \\
\hline $\mathrm{AB}$ & 18 & $28.0 \times 10^{7}$ \\
\hline St & $44^{*}$ & $4.7 \times 10^{7 *}$ \\
\hline
\end{tabular}

* From Matheson, et al. ${ }^{26}$

Table IV. Unpaired electron density of polymer ends, cross-propagation rate constants, and 1,4-contents of polymers

\begin{tabular}{|c|c|c|c|}
\hline \multirow{2}{*}{ Monomer } & \multirow{2}{*}{$\rho$} & $k_{21}$ & 1,4-Content \\
\hline & & $\mathbf{M}^{-1} \mathrm{~s}^{-1}$ & $\%$ \\
\hline EEP & 0.488 & 0.9 & 100 \\
\hline EMP & 0.484 & 2.8 & 90 \\
\hline EP & 0.480 & 5.4 & 80 \\
\hline $\mathrm{AB}$ & 0.613 & 10.1 & 62 \\
\hline MMA & 0.785 & $667^{\mathrm{b}}$ & \\
\hline VAc & 0.978 & $1014 \times 10^{2 \mathrm{~b}}$ & \\
\hline
\end{tabular}

a $k_{\mathrm{p}}$ (styrene) $=44 \mathrm{M}^{-1} \mathrm{~s}^{-1}$.

b From Polymer Handbook: ${ }^{25} \mathrm{MMA}, k_{\mathrm{p}}=310 \mathrm{M}^{-1} \mathrm{~s}^{-1}$, $r_{2}=0.54 ; \mathrm{VAc}, k_{\mathrm{p}}=1012 \mathrm{M}^{-1} \mathrm{~s}^{-1}, r_{2}=0.01$.

and with their corresponding propagating radicals can be estimated from $1 / r_{1}$ and $r_{2}$, respectively. The radical reactivity of diene compounds is much more than that of styrene and decreases as EMP $\approx \mathrm{EEP}$ $>\mathrm{EP}>\mathrm{AB} \geq \mathrm{Bu}$. The rate constants for radical polymerizations of these compounds were estimated by the rotating sector method. The average values of five runs are shown in Table III. The values of $k_{\mathrm{p}}$ for these compounds were smaller than that of styrene inspite of their higher reactivity toward a free radical, as shown by $1 / r_{1}$ values. Since the temperature dependence of the reactivity ratio was very small, the reactivity of the propagating radical can be understood from $k_{21}$, calculated from $k_{\mathrm{p}}$ $\left(25^{\circ} \mathrm{C}\right)$ and $r_{2}\left(60^{\circ} \mathrm{C}\right)$. The values of $k_{21}$, shown in Table IV, are much smaller than $k_{\mathrm{p}}$ for styrene. Thus, the reactivity of the propagating radicals of diene compounds toward styrene is much lower than that of the polystyryl radical.

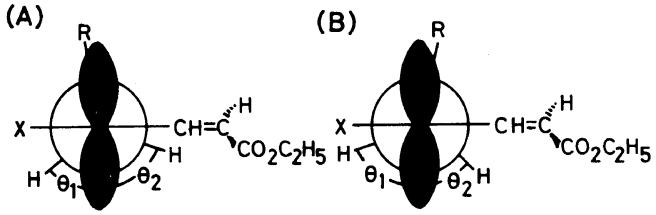

Figure 7. Possible conformations of allylic radical.

\section{DISCUSSION}

\section{Propagating Radical Conformation}

The hyperfine splitting constants of the methylene protons adjacent to the propagating radicals (allylic radicals) facilitate a conception of the molecular geometry of the radical ends. ${ }^{1,2,26}$ The nonequivalency of the hyperfine splitting constants of two methylene protons $\left(\mathrm{A}_{\mathrm{H}^{4}}\right.$ and $\left.\mathrm{A}_{\mathrm{H}^{5}}\right)$ suggests that the radicals do not freely rotate about the $\mathrm{C}(\gamma)-\mathrm{C}(\delta)$ bond at $-120^{\circ} \mathrm{C}$ (Table I). The dihedral angles $(\theta)$ between the $\mathrm{C}(\delta)-\mathrm{H}$ bond and $P_{\mathrm{z}}$ orbital direction projected on the plane perpendicular to $C(\gamma)-C(\delta)$ bond were determined by the expression $A_{H}=$ $\mathrm{B} \rho \cos ^{2} \theta$ where $\mathrm{B}$ is 58.6 Gausss and $\rho$, the spin density on $\mathrm{C}(\gamma)$. The $\mathrm{A}$ and $\mathrm{B}$ conformations, in which the values of $\theta_{1}$ and $\theta_{2}$ are the inverse of each other, are possible in all the propagating radicals (Figure 7). However, it should not be assumed that the two conformations are equal in free energy, since the steric repulsion between substituents bound to the radicals differs. When the propagating radical has two conformations, there are two different pairs of the $\theta_{1}$ and $\theta_{2}$ values in the ESR spectrum, as shown in the case of methacrylates. ${ }^{13,14}$ Since the observed spectra of diene compounds were simulated not with two but only a single conformation, the population of one of the two possible conformations should be negligibly small compared to that of the other conformation, even if the two conformations are possible. Accordingly, the observed ESR spectra were interpreted in terms of a single conformation. The choice between A and B was made by taking into account the steric repulsion between the substituents. A is energetically more favorable in both $\mathrm{EP}$ and $\mathrm{AB}$. In addition, the larger values of $\theta_{1}$ for EEP and EMP, compared to those of EP and $A B$, are due to conformation $A$ because of the increase in steric repulsion between $\mathrm{R}$ and $\mathrm{X}$ with the substitution of $\mathrm{H}$ atoms by methyl or ethoxy groups (Figure 8). Therefore, the most probable confor- 

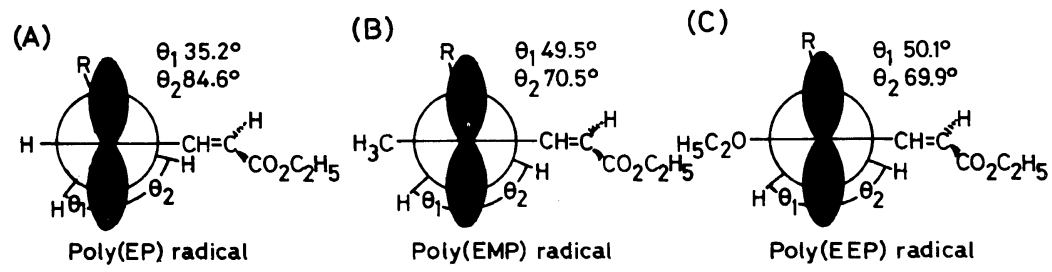

Figure 8. Optimum conformations of polydiene radicals in frozen benzonitrile at $-120^{\circ} \mathrm{C}$.

Table V. Polymer end conformations

\begin{tabular}{lcc}
\hline Monomer & $\theta_{1}$ & $\theta_{2}$ \\
\hline EEP & $50.1^{\circ}$ & $69.9^{\circ}$ \\
EMP & $49.5^{\circ}$ & $70.5^{\circ}$ \\
EP & $35.2^{\circ}$ & $84.8^{\circ}$ \\
AB & $35.2^{\circ}$ & $84.8^{\circ}$ \\
VAc & $53.1^{\circ}$ & $66.9^{\circ}$ \\
\hline
\end{tabular}

mation of the radical ends is A and the dihedral angles are shown in Table V.

\section{Unpaired Electron Density and Reactivity of Radical Ends}

Since a hyperfine splitting constant of $\alpha$-proton is proportional to the spin density on the carbon atom adjacent to the proton, the spin densities of the chain ends $\left(\mathrm{C}_{\alpha}\right)$ of diene compounds and VAc were estimated from $A_{\mathrm{H}^{1}}$ values, using McConnell's relation. ${ }^{28}$ The results are shown in Table IV along with those for MMA. Since the poly(MMA) radical has no proton adjacent to the radical end, the spin density was obtained from the hyperfine splitting constant of methyl protons using the relation, $\mathrm{A}_{\mathrm{CH}_{3}}=58.6 \rho \cos ^{2} \theta$ with $\theta=45^{\circ}$ for the free rotating methyl group, ${ }^{29}$ where $\rho$ is the electron density of the radical end and $\theta$ is the dihedral angle. The spin density decreases as VAc $>$ MMA $>$ AB $>$ EEP $\simeq \mathrm{EMP} \simeq \mathrm{EP}$. Since the propagating radicals of diene compounds are allylic and an unpaired electron is delocalized over the three carbons, the spin density at the radical ends is lower than that of MMA or VAc, where an unpaired electron is restricted for the most part to the chain end. The larger electron density of $\mathrm{AB}$ than $\mathrm{EP}$ is due to the fact that the acetoxy group has a less electronaccepting capacity than the carboethoxy group. The order of electron density among EEP, EMP, and $\mathrm{EP}$ is consistent with that of the electron-donating ability of the substituents of the allylic radical but the difference in spin densities seems too small to be of any importance.

Spin density may possibly be correlated with the reactivity of the propagating radical. The value of $k_{21}$ reflects the reactivity of the resulting radical. The order of spin density was not completely consistent with that of $k_{21}$ of VAc, MMA, and diene compounds. However, spin density values of EP, EMP, and EEP should be regarded the same. Accordingly, spin density seems to reflect the reactivity of the radical end, since the decreasing order of $k_{21}$ for VAc $(101,200)$, MMA (667), AB (10.1), and EP (5.4) is consistent with the decreasing order of spin density (Table IV). The difference in $k_{21}$ among EP, EMP, and EEP is probably caused by variation in bulkiness of the substituents at the 3 position. The ratio of the 1,4-addition unit to that of 3,4-addition unit in diene polymers is lower with increasing $k_{21}$, as shown in Table VI, and this is consistent with the general rule ${ }^{30}$ that selectivity in competing reactions decreases with increasing reactivity of the attacking reagent.

Acknowledgements. We should like to thank professors Yukio Kurita (Yokohama National University) and Koichi Hatada (Osaka University) for his reading of this manuscript and providing valuable comments. This research was supported in part by a Grant-in-Aid for Scientific Research from the Ministry of Education, Science and Culture of Japan.

\section{REFERENCES}

1. B. Rånby and J. F. Rabek, "ESR Spectroscopy in Polymer Research," Springer-Verlag, Berlin, 1977.

2. H. Fischer, Adv. Polym. Sci., 5, 463 (1968).

3. S. E. Bresler, E. N. Kozbekov, V. N. Fomichev, and V. N. Shadrin, Makromol. Chem., 175, 2875 (1974).

4. S. E. Bresler, E. N. Kozbekov, and V. N. Shadrin, 
Vysokomol. Soyedin Ser. A, 17, 507 (1975).

5. M. Kamachi, Y. Kuwae, and S. Nozakura, Polym. J., 14, 749 (1982).

6. J. H. O'Donnel, B. McGrarvey, and H. Morawetz, J. Am. Chem. Soc., 86, 2322 (1964).

7. J. Sohma, T. Komatsu, and H. Kashiwagi, J. Polym. Sci., B, 3, 287 (1965).

8. C. H. Bamford, A. Bibby, and G. C. Eastmond, Polymer, 9, 629 (1969).

9. M. Iwasaki and Y. Sakai, J. Polym. Sci., A-1, 7, 1537, 1747 (1972).

10. C. Chachaty and A. Forchini, J. Polym. Sci., A-1, 10, 1905, 1923 (1972).

11. L. Muszkat, J. Phys. Chem., 85, 2916 (1981).

12. M. J. Bowden and J. H. O'Donnell, J. Phys. Chem., 72, 1577 (1968).

13. M. Kamachi, M. Kohno, D. J. Liaw, and S. Katsuki, Polym. J., 10, 69 (1978).

14. M. Kamachi, Y. Kuwae, and S. Nozakura, Polym. J., 13, 919 (1981).

15. M. Kamachi, R. Miwa, and S. Nozakura, Polym. J., 12, 899 (1980).

16. O. Wichterle and M. Hudlicky, Collect. Czech., 12, 564 (1947).

17. M. Kamachi, J. Satoh, and S. Nozakura, J. Polym. Sci., Polym. Chem. Ed., 16, 1789 (1978).
18. M. Kamachi, D. J. Liaw, and S. Nozakura, Polym. J., 11, 921 (1979).

19. M. Kamachi, H. Umetani, and S. Nozakura, to be published.

20. L. M. Jackman and S. Sternhell, "Application of Nuclear Magnetic Resonance Spectroscopy in Organic Chemistry," Pergamon Press, Oxford, 1969.

21. L. J. Young, "Polymer Handbook," 2nd Ed, J. Brandrup and E. H. Immergut, Ed., John Wiley, New York, N. Y., 1975, p II-398.

22. R. Fujio, H. Satoh, and T. Tsuruta, Kogyo Kagaku Zasshi, 69, 2315 (1966).

23. M. Fineman and S. D. Ross, J. Polym. Sci., 5, 259 (1950).

24. T. Kelen and F. Tüdõs, J. Macromol. Sci. Chem. Ed., A9, 1 (1975).

25. Reference 20, Butadiene, p II-155 and p II-398.

26. M. S. Matheson, E. E. Auer, E. B. Bevilacqua, and E. J. Hart, J. Am. Chem. Soc., 73, 1700 (1951).

27. Reference 20, MMA, p II-47 and II-257; and VAc, p II-50 and II-364.

28. C. Heller and H. M. McConnell, J. Chem. Phys., 32, 1535 (1960).

29. H. Fischer, Z. Naturforsch, 19a, 866 (1966).

30. G. W. Klumpp, "Reactivity in Organic Chemistry," John Wiley, New York, N. Y., 1982, pp 352-353. 